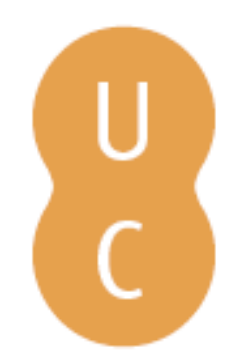

\title{
nommalina
}

\section{Narraciones del retorno: Vintila Horia y la recreación mítica del exilio en Un sepulcro en el cielo (1987)}

\author{
Autor(es): $\quad$ Cerullo, Luca
}

Publicado por: Imprensa da Universidade de Coimbra

URL

persistente: URI:http://hdl.handle.net/10316.2/44004

DOI: $\quad$ DOI:https://doi.org/10.14195/978-989-26-1550-9_2

Accessed : $\quad$ 26-Apr-2023 15:47:36

A navegação consulta e descarregamento dos títulos inseridos nas Bibliotecas Digitais UC Digitalis, UC Pombalina e UC Impactum, pressupõem a aceitação plena e sem reservas dos Termos e Condições de Uso destas Bibliotecas Digitais, disponíveis em https://digitalis.uc.pt/pt-pt/termos.

Conforme exposto nos referidos Termos e Condições de Uso, o descarregamento de títulos de acesso restrito requer uma licença válida de autorização devendo o utilizador aceder ao(s) documento(s) a partir de um endereço de IP da instituição detentora da supramencionada licença.

Ao utilizador é apenas permitido o descarregamento para uso pessoal, pelo que o emprego do(s) título(s) descarregado(s) para outro fim, designadamente comercial, carece de autorização do respetivo autor ou editor da obra.

Na medida em que todas as obras da UC Digitalis se encontram protegidas pelo Código do Direito de Autor e Direitos Conexos e demais legislação aplicável, toda a cópia, parcial ou total, deste documento, nos casos em que é legalmente admitida, deverá conter ou fazer-se acompanhar por este aviso. 


\section{Desplazamientos de la tradición clásica en las culturas hispánicas}

Paola Bellomi, Claudio Castro Filho, Elisa Sartor (eds.)

IMPRENSA DA UNIVERSIDADE DE COIMBRA 


\title{
Narraciones del retorno. Vintila Horia y la recreación MÍTICA DEL EXILIO EN UN SEPULCRO EN EL CIELO (1987) (Narratives of return: Vintila Horia and the mythic re-creation of exile in $U n$ sepulcro en el cielo (1987))
}

\author{
Luca Cerullo \\ Universidad de Nápoles “L'Orientale” (Orcid: 0000-0002-5108-8511)
}

\begin{abstract}
Resumen: E1 escritor y pensador rumano Vintila Horia, afincado en España desde 1953, pertenece a un grupo de escritores, pensadores e intelectuales que sufrieron, en el siglo XXI, las llagas del exilio. Su última novela, escrita directamente en español, nos cuenta los últimos días del pintor El Greco. El diario, escrito en un estilo refinado y algo experimental, refleja las inquietudes tanto del pintor griego como del propio Vintila Horia, pero, al mismo tiempo, se deduce el amor que el autor rumano siente por España, su tradición, sus mitos y su espíritu. A través de esta identificación novelesca con El Greco, el escritor rumano da lugar a su epitafio — no volverá escribir ni a publicar hasta su muerte-, dejando al mundo de las letras hispánicas un libro de difícil catalogación, pero de amplia y extensa posibilidad hermenéutica que hoy en día es, como toda la obra del autor rumano, objeto de una profunda revaloración crítica.

Palabras clave: Vintila Horia, exilio, El Greco, retorno, mito.
\end{abstract}

Авsтract: Rumanian writer Vintila Horia, established in Spain in 1953, belongs to a group of writers/thinkers who experienced exile in the $21^{\text {st }}$ century. His last novel, Un sepulcro en el cielo, written in Spanish, provides an account of painter $\mathrm{E} 1 \mathrm{Greco}$ 's last days in a vivid and, at times, very innovative language. Aside from providing an account of the concerns afflicting both E1 Greco and the author himself, the book is a testimony of the love Horia felt for Spain and its traditions, myths and spirit. This fictional identification with El Greco is Horia's epitah - he would not write or publish anything else until his death. He leaves us with a book which is difficult to categorise but that certainly provides - as is the case with all his literary work - multiple hermeneutical possibilities, all of them now being explored.

Keywords: Vintila Horia, exile, E1 Greco, return, myth.

\section{BiogR AFÍA DE UN “NUEVo” AUTOR}

Vintila Horia Caftangioglu llega a España en 1953, aunque su exilio empieza en 1944, cuando la guerra mundial causa la fractura del mundo en dos bloques antagónicos. Rumanía, su país natal, pasa a ser un país filosoviético y él, para nada a favor del nuevo escenario, decide no volver a casa.

Italia y Argentina protagonizan la etapa inicial de su exilio. Una época en la que, junto a su esposa Olga, Vintila Horia vive el hambre y la miseria. En la 
Italia de posguerra nada le hace esperar un futuro mejor y en Argentina solo consigue trabajos provisionales, aunque su capacidad para resistir las circunstancias históricas, uno de los ejes temáticos de su futura trayectoria literaria, se hace evidente y le ayuda a mirar adelante. La ocasión de volver a Europa, que Vintila Horia admira tanto, se presenta tras el diagnóstico de un asma crónico. $\mathrm{Su}$ mujer, Olga, no puede aguantar la humedad y el clima bonaerense. Tras un largo viaje de vuelta, la pareja se instala en Madrid. Aquí, Vintila Horia asentará su residencia de exiliado y, después de no mucho tiempo desde su llegada, vuelve a escribir. Cuentos, novelas, pensamientos, se mezclan en las varias lenguas que ha ido adquiriendo durante la guerra y el exilio. La trayectoria literaria del autor presenta un problema de catalogación; en su extenso corpus se cuentan obras escritas en varios idiomas y pertenecientes a diversas corrientes literarias que quizá imposibiliten cierta integración a uno u otro género. Lo que sí cobra interés es, por lo tanto, no el ámbito de pertenencia, cuya importancia se relativiza al entender que se trata de un autor que de forma voluntaria rechaza cualquier acto de afiliación, sino el mensaje que el mismo proceso literario conlleva. Convencido de que la escritura, sobre todo la novela, es una "técnica de conocimiento", Vintila Horia da lugar una novela que se somete a varios prismas hermenéuticos, puesto que es no tanto un acto de creación sino el producto de una meditación, de un análisis que se pone en marcha a partir de un problema o de un conflicto. Tal esencia del libro horiano propicia, pues, la coexistencia de diferentes planos de interpretación, una capacidad multifacética que acaba de ser descubierta en ámbito crítico.

En 1960, tras mandar el borrador a varias editoriales francesas, su novela Dieu est né en exil se publica por la parisina Fayard y un año más tarde, la novela gana el premio Gouncourt. El premio, que finalmente el escritor rumano rechaza por no someterse al juego intelectual ocasionado por la izquierda intelectual francesa —entre todos Sartre, que le acusa de ser nazista—, le proyecta en el universo de los grandes novelistas, hoy olvidados, del siglo XX. Seguirá una extensa y larga trayectoria literaria que acabará en 1987, cuando el autor publique su último trabajo, Un sepulcro en el cielo.

\section{UNA INTENSA ACTIVIDAD CULTURAL}

Para nada aislado de la vida social del nuevo espacio, Vintila Horia da comienzo a una intensa actividad cultural, con el afán de crear, en el Madrid de comienzos de los cincuenta, una comunidad cultural rumana en el exilio. La capital española acoge, pues, a varios intelectuales rumanos que han optado por la España de Franco, una situación propiciada por el hecho de que el país ibérico es el único que les acoge sin problemas (Behring, 2001). En torno a Vintila Horia, Gheorghe Uscatescu y Alexandru Busuioceanu se reúnen todos los exiliados rumanos y en poco tiempo, gracias sobre todo al dinamismo de Vintila Horia, la 
comunidad rumana en Madrid se convierte en uno de los centros de referencia para la Rumanía de la diáspora.

Muy pronto, el autor rumano traba amistad con el entorno intelectual español. Amistades que le facilitan el acceso a la cátedra universitaria de Literatura Universal en la Complutense, a cargos en el CSIC y a la publicación en revistas de varios artículos de corte literario, político y filosófico. Es, por lo tanto, un intelectual completo, capaz de abarcar, con tranquilidad, varios ámbitos de investigación, para nada colocado en un solo sector de interés.

$\mathrm{Su}$ trayectoria novelística se concluye, como dijimos, con la novela Un sepulcro en el cielo, escrita quizás en una época de profundo pesimismo: el regreso al país natal ya se ha convertido en una utopía (lleva casi cincuenta años fuera de su país) y el mundo que ha conocido y que ha trasformado en su refugio, España, vive un momento de profunda trasformación social, caracterizado por una crisis política que reduce el impacto social del clima dinámico de la Transición democrática. El exilio, podemos afirmar, representa ahora su verdadera patria, su único espacio. El retorno imposible a Rumanía se desarrolla tanto sobre el plano espacial como el espiritual. Es decir, si por un lado Rumanía es inalcanzable desde el punto de vista material, por estar sometida a la misma dictadura hostil al entorno del autor, también resulta imposible un tipo de retorno "psicológico", donde el autor se relacione con su pasado, con su memoria. De ahí que el retorno, como veremos, solo se realice en lo trascendental, en la dimensión del "más allá" que, en nuestro autor, coincide con la visión cristiana del mundo.

La desilusión para la época que Vintila Horia está viviendo se percibe también en la novela: el título hace referencia, de hecho, a la posibilidad única de salvación, ya presente en otras obras del autor: el mundo celestial. Una idea que Vintila Horia hace suya gracias a su sincera fe religiosa, que se advierte en toda su trayectoria de novelista y de pensador. Hay que decir que él nunca ha afirmado ser de confesionalidad católica u ortodoxa, aunque queda bastante claro que su perspectiva teológica no prescinde de tal división.

\section{UN SEPULCRO EN EL CIELO}

La novela se inserta en un modelo que Vintila Horia ya ha usado para otras narraciones, es decir, el diario apócrifo de los grandes exiliados de la historia. Tras contar el exilio de personajes como Ovidio (Dieu est né en exil) o Platón (Le septième lettre) Vintila Horia decide investigar sobre una de las figuras históricas que más le han interesado: El Greco.

$\mathrm{E}$ l interés por el pintor cretense viene de lejos: entre los varios mundos que Vintila Horia explora, la pintura es uno de los más apreciados. Admirador de la pintura clásica, del arte religioso de la Edad Media, de pinceles como Goya, considera la pintura una de las formas más altas de arte, tal vez imposible de descifrar de manera completa. 
Asimismo, el hecho de adueñarse de la voz de los exiliados de la historia se convierte en su misión principal. Es una manera de exorcizar su propio exilio, transformar su propia experiencia en universal y otorgarle a la vida un sentido que vaya mucho más allá de la mera supervivencia o estancia en el mundo. Una voluntad de trascendencia que caracteriza su entera experiencia vital y literaria y que muy a menudo coincide con una visión cristiana del mundo.

En 1985, dos años antes de que publicara Un sepulcro en el cielo, Jesús Fernández Santos publica El Greco, una versión novelada de la vida del pintor, que Vintila Horia tiene la ocasión de reseñar para El Alcázar. En esta ocasión, aunque Horia repite que el libro le "ha gustado", no deja de manifestar cierto escepticismo sobre la novela y la manera de tratar la figura del pintor, convencido de que

Es El Greco uno de los personajes más complicados, más difíciles de entender, más lleno de trampas vitales y artísticas de la historia de la pintura, porque lleva en sí una carga de complejos que los críticos están desvelando a lo largo y ancho de su pintura, quedando la otra, los complejos vitales, al alcance de pocos, ya que escasos testimonios nos han quedado de su existencia terrenal. (Horia 1985)

Probablemente, cuando escribe la reseña, Vintila Horia esté ya pensando en su próxima novela, ya que va remarcando faltas, lagunas y errores históricos que Fernández Santos comete en su propia versión. Le acusa de insertar una historia de amor no comprobada entre Jerónima de las Cuevas y Francisco Preboste, el ayudante de El Greco, además de confundir las escuelas que el pintor frecuentó y sus relativos conocimientos. Se denota, por lo tanto, no solo un interés especial por El Greco, sino un conocimiento casi académico, que no admite faltas o aproximaciones:

La novela de Jesús Fernández Santos es uno de los mejores libros del autor, a menudo apasionante, escrito en un idioma rico, suculento, representativo de los personajes que maneja con verdadera maestría, pero sin lograr acercarse mucho al misterioso y secreto protagonista. (Horia 1985)

Sin embargo, no podemos hablar de novela histórica. La contextualización, los detalles, las referencias históricas solo sirven para una construcción textual y de los personajes. Además, el deseo de universalización de la condición de exiliado no puede conllevar, por su propio estatus paradigmático, la precisión histórica.

Editado por Planeta, Un sepulcro en el cielo sale, como se ha dicho, en 1987 y puede considerarse como síntesis de la trayectoria literaria del autor, pero al mismo tiempo una manera para trazar un balance de su propia existencia de 
exiliado. Vintila Horia se despide de la escena literaria, a la que no deja de detectarle cierta sumisión al mercado, con una novela compleja y enriquecida de enigmas, elementos que, quizás adrede, no encuentran solución.

El libro se compone de cinco capítulos correspondientes con etapas vitales del pintor. Los capítulos centrales, desde el segundo al cuarto, recuerdan a obras de El Greco: "El Expolio", "El Martirio” y "El Entierro", cuadro este último que reaparece en la portada del libro y que representa quizás el sentido real que Vintila Horia, adueñado de las palabras del pintor, quiere darle al diario. "El Entierro del Conde de Orgaz" es, en efecto, la representación más fiel de una época en que se representa también el entierro simbólico de España y de su proyecto imperial:

El entierro del Conde de Orgaz es la culminación de un sueño que se frustra en la tierra para cumplirse en el cielo. (Horia 1985)

Se entrecruzan una visión horizontal del mundo, visión del Humanismo de tipo renacentista, y otra vertical heredada de la Edad Media. Todo esto, además de ser el perno sobre el que gira la pintura de El Greco, corresponde también con la visión de Vintila Horia de la existencia como grande e inacabado conflicto entre Dios y el Hombre.

Hablamos de síntesis porque en Un sepulcro en el cielo se reúnen todos los elementos que pueden detectarse en la novelística horiana. En primer lugar, el diario apócrifo. Emilio Del Río, profesor y pensador de los años sesenta, ha afirmado que en las novelas de Vintila Horia se cumple una posible "fusión mítica", es decir, a través de la historia, escrita en primera persona, de una figura que ha protagonizado la historia, el autor consigue mandar un mensaje universal, quedando manifiesta la posibilidad de identificación entre personaje histórico y el escritor mismo (Del Río 1971). De esta manera, la distancia entre autor y personaje se reduce, llegando a una identificación casi total. La figura de El Greco es perfecta para encajar en este juego o fórmula literaria: es "un exiliado, parecido a los que hoy abandonan el Este para volver a encontrar o para conseguir su libertad en los puertos occidentales, todavía libres" (Horia 1985), con que el autor establece, en seguida, cierta afinidad. Como él, El Greco decide viajar hacia Occidente, refugiarse en otro espacio y en otra lengua, sin olvidar sus propios orígenes. Como el mismo Horia, El Greco pasa por Italia pero de ahí a poco la abandona para llegar a ese espacio lleno de misterio y de incertidumbre que es España. El exilio de El Greco no es tan distinto del de Vintila Horia. Ambos viven en una España en que la confesionalidad se presenta como eje vital y donde nacen y se desarrollan sueños imperiales de grandeza y triunfos: la España del Siglo de Oro, para El Greco, la España franquista, para Vintila Horia: 
España, la del tiempo del Greco, hubiera podido rehacer la unidad perdida, incluyendo en su área imperial a un Bizancio reconquistado (hazaña posible después de Lepanto) y a Inglaterra, bastión de la Reforma y del puritanismo más tarde. Europa hubiera podido estar unida si España cumple con todas las promesas. El imperio romano cristianizado fue el núcleo de aquel sueño, luego Bizancio, luego el imperio alemán de la Edad Media. Pero intervino la separación entre Roma y Bizancio, luego la caída inevitable de este y, más tarde, la ruptura luterana. Roma, Rusia y los anglosajones otorgan matices distintos a un fondo común al que tratamos desesperadamente de reconstituir hoy, a través de instituciones laicas que no vienen al cuento. Por este motivo, el Greco es tan grande. Su propio mundo interior, su cultura, su formación, su inconsciente colectivo forman una personalidad que procede de muy lejos. Es el fondo helénico del pintor, al que se sobrepone su catolicismo cretense, luego su presencia en Venecia y en Roma, y, por fin, en Toledo, en un momento crucial de la historia europea, cuando España da al mundo reyes, guerreros, descubridores, místicos, dramaturgos, novelistas, juristas, técnicos, médicos, marinos que constituyen de por sí un imperio cultural, una civilización, la primera de tipo realmente universal. El pintor asiste al desarrollo del tymos castellano, del plan vital como decía Platón, su compatriota, y pinta por encima de la imaginación del rey que forja el imperio pero quizá no lo comprende más que como un amasijo territorial. Todo es tragedia en la vida del griego y nada se cumple, ni el amor ni la ecúmene. Sólo en "El entierro..." se realiza plenamente, tiene la certeza de haber pintado una obra maestra, más grande que la Capilla Sixtina. Su fracaso, que rima con el fracaso del tymos castellano, es grandioso, pero, de la misma manera en que España crea un siglo de oro, que es toda una época de plenitud dentro de la cultura occidental y, hasta en el fracaso, sigue engendrando genios, El Greco da con su Siglo de Oro en la simbología, $\tan$ compleja y tan extraordinaria, de su "Entierro del señor de Orgaz". Hay un paralelismo estremecedor, una correspondencia viviente entre un conjunto nacional, en tensión universal, y el yo de un artista que, al coincidir con la visión española del mundo, se vuelve pintor genial. (Horia 1987: 189)

Escritor y personaje, por lo tanto, se acercan hasta representar la doble cara de la misma moneda. Es esta una técnica muy frecuente en Vintila Horia, cuyo deseo de interpretar las razones por las cuales se desarrolla el proceso histórico le lleva a adueñarse de las mismas dudas y meditaciones que, según él, afectaron a los grandes exiliados de la historia. No es casual que el único canon en que el autor de verdad se reconoce sea él de la así llamada, y para nada exitosa, novela metafísica, un tipo de novela que cuenta con varios escritores, aunque muchos de estos solo de forma provisional o accidental, y que se desarrolla a partir de los años sesenta. El exégeta máximo, y también escritor de este reducido grupo intelectual es Manuel García Viñó, quien, no sin matices muy polémicos, ironiza sobre otros tipos de novelas presentes aún hoy en España, más rentables y 
comerciales pero desprovistas de sentido y de cualquier mensaje. Para Horia, en cambio, de acuerdo también con los autores metafísicos, la novela tiene que ser una técnica de conocimiento, un lugar donde el autor no puede permitirse el lujo de limitarse a lo descriptivo, sino abrir brechas en el pensamiento, buscando los límites conceptuales del ser humano y finalmente encontrar respuestas a las inquietudes que mueven el alma de quien escribe. Una misión, por tanto, de la que el escritor tiene que hacerse cargo:

El escritor es el único representante de un arte capaz de abarcar todo y de absorber y recrear la realidad, posibilidad que ninguna otra técnica de conocimiento, la ciencia, por ejemplo, podría nunca aspirar a asumir. (Horia 1978: 33)

Para dar seguimiento a la idea de que estamos frente a una recreación mítica del exilio, señalemos que la historia que se cuenta en Un sepulcro en el cielo está llena de referencias de tipo filosófico-existencial. El pintor se pregunta el porqué de una peregrinación continua, reiterada, que no aniquila el pesimismo frente a un mundo que se muestra cada vez más indescifrable:

¿Quién soy yo, al lado y bajo la luz de este cuadro? ¿Por qué he tenido que abandonar mi tierra y venir a vivir tan lejos de ella, en el otro extremo de Europa y del Mediterráneo, mientras crece entre una y otra la oleada de la invasión infiel? ¿Tiene esto algún sentido? (Horia 1987: 36)

La falta de sentido parece una obsesión para cualquier exiliado. La ausencia, pues, de un mundo al que dirigirse y de coordenadas espaciotemporales en las que reunir sus propios pensamientos, emociones, vivencias. A través de la palabra, aquí algo novelada, de El Greco, Vintila Horia da voz a su propio exilio, y sobresale la idea de que el mundo se rige al azar, una casualidad que hizo que un pintor cretense del siglo XVII y un escritor-filósofo del siglo XX coincidiesen en el mismo lugar de exilio, compartiendo análogos conflictos interiores:

Mi pasado griego (o rumano, el de Horia) empezaba a esfumarse tras una niebla parecida a la que limitaba mi visión en aquel momento. Ya en Toledo me había dado cuenta de esta lenta separación, pero no había remedio, mi persona se identificaba cada vez más con el sitio y este con el idioma que había impuesto a los hombres, o éstos a él. El destierro se volvía arraigo y yo no lo lamentaba de ninguna manera. Los colores, además, no se expresan en palabras vinculadas a un espacio. Solo los escritores deben padecer el dolor del desarraigo. (Horia 1987: 173)

Un arraigo que parece aquí inevitable, como si España, la de El Greco y la de Vintila Horia, fuese el único espacio posible, una idea que no se aleja mucho 
de la realidad de ambos casos. Para el pintor, las Cortes representan la meta final de un trayecto artístico lleno de conflictos, que lo hizo escapar del "cauce humanista" italiano y, sobre todo, del atraso del mundo oriental del que procede. En el caso de Horia, en cambio, España es el país donde, tras la segunda guerra mundial, se han quedado vivos valores como el catolicismo conservador y cierta idea del mundo para nada relacionada con lo que está aconteciendo en el resto de Europa. Es este un paralelismo bastante claro: El Greco y Vintila Horia huyen de un lugar centro-oriental porque lo consideran un sitio todavía "salvaje" y, desde el punto de vista tanto cultural como artístico, analfabeto. Ambos llegan luego a Italia, donde a pesar de la admiración que tienen por el país, su cultura y su arte, se ven metidos en un ambiente que les es bastante hostil. El Greco lamenta la distancia de su idea de pintura con el grupo italiano, con quien no comparte ideas artísticas:

Roma había dejado de interesarme, no la veía ya, me encontraba solo entre nobles, príncipes de la Iglesia y artistas que se ufanaban en copiar el mundo exterior y se dedicaban a echar a Dios de los templos a golpes de humanismo. (Horia 1987: 15)

Para Vintila Horia tampoco Italia es una etapa feliz. Ahí empieza su exilio, cuando en 1944 tiene que cruzar un país bombardeado y escapar de un campo de concentración para diplomáticos. Asiste a la destrucción física y moral de una tierra que siempre ha admirado, pero que ahora le es ajena: en la Academia Rumana en Roma rechazan hospedarle, en Toscana encuentra cobijo y un sueldo muy bajo por colaborar con revistas de cultura, gracias a la ayuda de Giovanni Papini, pero su estancia en Italia queda como el período más trágico de su exilio, lo que le convence a huir hacia otras orillas, concretamente Argentina, donde se quedará hasta su llegada a España. Con Italia ambos artistas entrelazan relaciones provisionales y efímeras, cuya esencia no logran entender por las circunstancias históricas que los rodean. Es, por lo tanto, la tierra de lo indescifrable, de la incomprensión. El mismo Vintila Horia será siempre algo nostálgico con respecto a Italia, su relación intrínseca con el país italiano permanecerá sometida al bucle de la incomunicación.

Se completa, de ese modo, el proceso de "fusión mítica". El exilio italiano de Vintila Horia se presenta enmascarado en el período italiano de El Greco, un esquema destinado a repetirse a lo largo de toda la novela. La operación de salida del país italiano es también traumática. Dentro del contexto de incomunicación se producen conflictos interiores que son evidentes:

Lo que descubrí en aquella época, tan concentrada en fechas y acontecimientos, constituyó para mí otro motivo de separación. De manera instintiva me había alejado del humanismo y de los ideales del siglo XV y desde Venecia, 
Florencia y Asís y todo lo que el viaje a Roma había significado para mí, la separación había empezado a producirse, pero fue durante aquellos meses en Roma, al amparo de Fulvio Orsini, cuando tomé las medidas de la catástrofe que el espíritu antiguo y su imitación, hasta en Miguel Ángel, habían producido en el alma de mis contemporáneos. Algo nuevo estaba en el aire romano y en su península en general, pero no lograba disipar las nubes oscuras del pasado más reciente. Una época sepulcral estaba agotando su ciclo histórico en nosotros, y desde esta clausura estaba brotando, como desde su interioridad visceral, el cuerpo nuevo de otra época, con la que yo me sentía profundamente vinculado. (Horia 1987: 89)

\section{El personaje femenino}

El papel de síntesis de la prosa de Vintila Horia es reforzado por la posición dentro de la narración de la figura femenina. La mujer es, para el autor, determinante para el proceso creador. Monica Nedelcu, autora del primer trabajo monográfico sobre el exiliado rumano (1988) afirma que la mujer tiene un papel fundamental en Vintila Horia. De hecho, la mujer se convierte en brújula para el refugiado, hasta representar, en varias ocasiones, a la patria misma. Es un proceso bastante común, donde el paralelismo patria-mujer queda bastante descifrable. En Dios ha nacido en el exilio, el encuentro del poeta Ovidio con Dokia, una muchacha del lugar del exilio, Tomis, es determinante para la integración con el nuevo entorno. En Perseguid a Boecio, donde se cuenta la puesta en libertad de un prisionero de los campos de concentración soviéticos, es una mujer, Malvina, la que hace sobrevivir al personaje. En Marta o la segunda guerra, historia de seis personajes que, por una razón u otra, acaban enamorándose de una mujer, esta es una identificación perfecta con la patria perdida, que todos los personajes comparten: Rumanía.

Monica Nedelcu ha dividido a las mujeres presentes en la narrativa de Vintila Horia en dos grupos: por un lado, la mujer que vive en la memoria: ausente, relacionada con el pasado, es una mujer-guía, que le sirve al protagonista para no olvidar su propio origen. Por otro, la mujer que vive en el presente: vehículo de integración y generadora de la fuerza necesaria de seguir adelante, a pesar de las llagas del exilio y de la separación (Nedelcu 1988). Jerónima de las Cuevas, mujer de El Greco, reúne las dos categorías, hasta romper tal separación, tan rígida hasta el momento en las novelas del autor. Es, al mismo tiempo, la mujer de la memoria, puesto que su ausencia está subrayada a lo largo de toda la novela, y la mujer gracias a la que el pintor conoce y traba amistad con el nuevo espacio:

¿Te acuerdas? Nadie me entendía, salvo tú y los toledanos, hubo desde el principio algo así como una corriente unificadora entre tu gente y yo [...] Y entonces fue cuando decidí crear un reino para mí, entre las murallas de Toledo, rodeadas por el recuerdo de tus brazos de mujer entendedora, 
generadora de milagros. Yo nací de aquel movimiento que, desde tus dedos, subía a mi cabeza y desentumecía mi cerebro, al que ni Venecia ni Roma habían logrado desentumecer. (Horia 1987: 13)

Más allá de esta división, la mujer de Vintila Horia sigue tres etapas de transformación. La primera evoca el binomio amor/fatalidad. Víctimas de la historia, hombre y mujer establecen un proceso de hermandad que de alguna forma propicia una relación única entre los dos. La fatalidad se traduce, tarde o temprano, en la separación; el encuentro entre hombre y mujer ya prevé que uno de los dos desaparezca para siempre, y la ausencia del personaje femenino ayuda a que se realice una proyección simbólica de este. En este sentido, la mujer de El Greco, Jerónima, es típicamente horiana. Su ausencia, repetida a lo largo de la novela, es el expediente para que El Greco encuentre las energías para seguir pintando, a pesar de la sensación de pesimismo y decadencia que él mismo ve a su alrededor.

El segundo estadio del amor, en Vintila Horia, se rige por el binomio amor/pasión. La sensualidad juega un papel fundamental en Horia: menudean encuentros amorosos, con largas descripciones y plenos abandonos al mundo de los cinco sentidos. Con Jerónima esta esfera del amor tampoco es marginal, aun cuando, en la última parte, se hace referencia a otro amor del pintor, Violeta Antigua. Jerónima no pierde su papel de mujer superior a las demás, punto principal de la pasión auténtica del pintor. El tercer estadio, el de amor/redención también es protagonizado por ella. Las mujeres de Horia son, en efecto, vehículo para la salvación, objeto de proyección para el mundo del más allá. Fiel a la visión cristiana del mundo, Vintila Horia no olvida subrayar que en la tierra solo se está de paso y que, sin duda, Jerónima de las Cuevas está esperando al pintor en el mundo celestial cuando este acabe su estancia en la tierra.

Se cumple así el esquema que en otras pruebas narrativas del autor no prevé la presencia de una sola mujer, sino de muchas, con el afán de colmar los vacíos de tipo existencial que afectan al protagonista. Jerónima de la Cuevas es, al mismo tiempo, el paradigma de la mujer horiana, objeto de pasión, de memoria y salvación eterna.

\section{LA PROYECCIÓN CELESTIAL}

El último capítulo del diario, titulado "El quinto sello", desplaza la narración a un momento algo posterior a los sucesos que se cuentan en la primera parte. Encontramos aquí a un Domenikos que acaba de cumplir setenta años, se siente viejo y afligido por una sensación de pérdida que quizás esté relacionada con la decadencia de España misma. En un coloquio con Miguel de Cervantes, El Greco le cuenta al escritor de su encuentro y su conversación con Francisco de Quevedo. Prevalece el carácter religioso, muy próximo al arrepentimiento de tipo cristiano del pintor, 
llegando este a identificarse con los mártires de Cristo. La proyección celestial es, pues, un eje fundamental del libro. Las frases finales lo explican muy bien:

Y me acordé la desgracia de Francisco de Quevedo y de lo mucho que tenemos que padecer, con el fin quizá de encontrar el camino hacia un sepulcro en el cielo con la mente pegada sin embargo en estas dos preguntas [...] ¿Qué va a ser del mundo sin mí? ¿Qué va a ser de mí sin el mundo? (Horia 1987: 334)

Conjeturando sobre una fe católica, que nunca ha quedado clara para El Greco, Vintila Horia intenta resolver uno de los grandes enigmas del exiliado: si habrá o no forma de compensación por las llagas del exilio. El exilio se presenta en su forma más simbólica, es decir, como proyección del camino terrenal de seres que tienen como destino final el paraíso. Es esta una de las razones que justifican la tesis según la cual Un sepulcro en el cielo, además de ser una novela escrita con magistral control del estilo y de la técnica narrativa, es sobre todo un intento de escribir una obra paradigmática para cualquier exiliado.

Desde esta perspectiva, la trayectoria del pintor griego, elegido a representante ejemplar del exilio, se trasforma en el recorrido terrenal de todo exiliado: al principio hay una traumática separación, que conlleva cierta pérdida de la memoria, del recuerdo de la patria natal. Aunque quedan en la memoria la nostalgia y el afecto, la separación de su propio país es vista como inevitable. Asimismo, hay una primera etapa, un exilio preparador que se presenta de forma casi inconsciente. Italia para el pintor, y para el escritor, cualquier otro país para otros exiliados: es este el peor momento, cuando quien se exilia toma conciencia del desplazamiento, de lo que significa enfrentarse a un mundo totalmente desconocido. Llega, más tarde, el exilio definitivo, el país elegido. Una tierra que, a pesar de una estancia que a veces es larga, incluso permanente, no deja de provocar violentos conflictos de tipo existencial. Finalmente, no puede faltar la proyección celestial, es decir, el traslado de estas elucubraciones a una esfera más alta, que dé justicia tras una larga estancia en la tierra de privaciones y ausencias.

Para concluir, Vintila Horia, a través de las palabras de Domenicos Thetokopoulis, logra una recreación del exilio. Un recorrido parecido, con las mismas reflexiones, idénticos malestares, el mismo nivel de fugacidad de momentos de dicha. Asimismo, a finales del libro, antes de firmar su despedida del mundo de la escritura, el autor intenta proponer una solución al exilio y a sus injusticias: que el mensaje cristiano se cumpla y abra las puertas a una compensación de tipo cristiano, sometiéndose completamente a la voluntad divina. 


\section{Bibliografía}

Behring, Eva (2001), Scriitori români din exil, 1945-1989, o perspectivă istoricoliterară. Bucarest: Fundației culturale române.

Del Río, Emilio (1971), Novela intelectual. Madrid: Prensa Española.

García Viñó, Manuel (1967), Novela española actual. Madrid: Guadarrama.

Horia, Vintila (1985), "El Griego", El Alcázar, consultable en http://vintila. blogspot.it/2008/06/el-griego.html, 30/11/16.

- (1978), Consideraciones sobre un mundo peor. Barcelona: Plaza \& Janès. (1987), Un sepulcro en el cielo. Madrid: Planeta.

(2011), Un sepulcro en el cielo. Madrid: E1 Buey Mudo.

Nedelcu, Monica (1989), La obra literaria de Vintila Horia. El espacio literario en cuatro novelas francesas. Madrid: Universidad Complutense [Tesis doctoral]. 